\title{
O nutricionista no programa de alimentação escolar: avaliação de uma experiência de formação a partir de grupos focais
}

\author{
The dietician in the school food program: \\ evaluation of a training experience \\ based on focus groups
}

\author{
Lígia Amparo da Silva SANTOS ${ }^{1}$ \\ Janaína Braga de PAIVA² \\ Adriana Lima MELLO' \\ Gardênia Abreu Vieira FONTES ${ }^{1}$ \\ Lilian Ramos SAMPAIO ${ }^{1}$ \\ Maria do Carmo Soares de FREITAS 1
}

\section{R E S U M O}

\section{Objetivo}

O estudo objetivou analisar os resultados relativos à avaliação de um Programa de Formação para Nutricionistas que atuam no Programa Nacional de Alimentação Escolar da região Nordeste. Este programa foi desenvolvido pelo Centro Colaborador em Alimentação e Nutrição do Escolar da Universidade Federal da Bahia em parceria com o Fundo Nacional de Desenvolvimento da Educação, nos idos de 2007 e 2008.

\section{Métodos}

Os dados foram produzidos através da técnica de grupos focais com nutricionistas que participaram do Programa de Formação. Foram realizados quatro grupos focais e os dados produzidos foram organizados em duas categorias de análise: sobre a aprendizagem durante a formação e sobre a capacidade de instituição de mudanças.

\section{Resultados}

Os participantes eram predominantemente do sexo feminino, com idade variando entre 20 e 35 anos e haviam participado do Programa de Formação pelo menos três meses antes do estudo. Em relação à avaliação do programa de formação, pôde-se afirmar que o mesmo não apenas proporcionou um aprimoramento técnico-

1 Universidade Federal da Bahia, Escola de Nutrição, Departamento Ciências da Nutrição. R. Araújo Pinho, 32, Canela, 40110-150 Salvador, Bahia, Brasil. Correspondência para/Correspondence to: LAS SANTOS. E-mails: <amparo@ufba.br>; <ligiaamparo@gmail.com>.

2 Nutricionista. Salvador, Bahia, Brasil. 
-científico em torno dos temas pertinentes à prática profissional exigida, mas também à dimensão éticopolítica do trabalho. Enfatizou-se que estimulou a mobilização na perspectiva do fortalecimento da categoria, incentivou as parcerias entre os diferentes agentes e setores e fomentou o planejamento de novas ações valorizando o uso da legislação.

\section{Conclusão}

A perspectiva dialógica foi marcante para os participantes, que puderam confrontar as suas realidades com as dos demais, possibilitando reflexão coletiva sobre a atuação do nutricionista no campo da alimentação escolar.

Termos de indexação: Alimentação escolar. Educação em saúde. Formação de recursos humanos. Nutricionista.

\section{A B S T R A C T}

\section{Objective}

This study assessed a training program for dieticians, actors of the Brazilian School Food Program, in Northeast Brazil. This program was developed by a partnership between the Schoolchildren's Food and Nutrition Collaborator Center from the Federal University of Bahia and National Education Development Fund, from 2007 and 2008.

\section{Methods}

The focus group method was administered to dieticians who participated in the training program. Four focus groups were done and the data were organized into two categories: one about learning during the training program and one about the ability to make changes.

\section{Results}

Most participants were females aged 20 to 35 years. Their participation in the training program had been at least three months before the study. Assessment of the training program showed that the program improved their technical and scientific knowledge about themes related to professional practice and about the ethical and political dimension of their work. The program encouraged mobilization for possibly strengthening the category, incentivized partnerships among different agents and sectors and promoted the planning of new law-enforcement actions.

\section{Conclusion}

The dialogical perspective was striking for the participants, enabling them to confront their realities and collectively reflect on the dietician's role in the field of school food.

Indexing terms: Nutritionist. Permanent education in health. In-service training program evaluate. School meal program.

\section{N T R O D U ÇÃ O}

Nos anos de 2007 e 2008, o Centro Colaborador em Alimentação e Nutrição do Escolar da Universidade Federal da Bahia (CECANEUFBA), em parceria com o Fundo Nacional de Desenvolvimento da Educação, Ministério da Educação (FNDE/MEC), desenvolveu um Programa de Formação para nutricionistas que atuavam no Programa Nacional de Alimentação Escolar (PNAE) da Região Nordeste. A parceria fora firmada em 2006, com a finalidade de prestar apoio técnico e operacional através da implementação de ações direcionadas a contribuir para a efetivação e con- solidação da Política de Segurança Alimentar e Nutricional no ambiente escolar e para o aperfeiçoamento do controle social e execução do PNAE. Entre essas ações, destacava-se a realização de cursos de formação para os atores envolvidos no Programa, dentre os quais nutricionistas, merendeiras, componentes do Conselho de Alimentação Escolar (CAE), diretores de unidades de ensino e coordenadores pedagógicos.

O Programa Nacional de Alimentação Escolar é um dos mais antigos programas sociais do governo brasileiro, sendo considerado no cenário mundial um dos maiores programas de atendimento universal na área de educação'. Ele tem 
por objetivo "contribuir para o crescimento e o desenvolvimento biopsicossocial, a aprendizagem, o rendimento escolar e a formação de práticas alimentares saudáveis dos alunos, por meio de ações de educação alimentar e nutricional e da oferta de refeições que cubram as suas necessidades nutricionais durante o período letivo" 2 (p.1). Destaca-se que em 2009 foram atendidos pelo Programa 47 milhões de alunos ${ }^{3}$.

Nas duas últimas décadas, o PNAE tem sofrido uma série de alterações em seu arcabouço legal como, por exemplo, a consolidação progressiva do nutricionista como responsável técnico pela alimentação escolar. Entre as atribuições desse profissional no âmbito do Programa, estão: coordenar o diagnóstico e o monitoramento do estado nutricional dos estudantes; programar, elaborar e avaliar os cardápios da alimentação escolar, tendo em vista a adequação aos perfis epidemiológicos e às faixas etárias das populações atendidas, o respeito à cultura alimentar de cada localidade e a vocação agrícola da região; acompanhar desde a aquisição dos gêneros alimentícios até a produção e distribuição da alimentação; propor e realizar ações de educação alimentar e nutricional nas escolas, de maneira a promover hábitos alimentares saudáveis ${ }^{4-6}$.

Costa et al. ${ }^{7}$ enfatizam que no PNAE o nutricionista tem a possibilidade de desenvolver papéis que vão além daquele relativo à administração de refeições que suavizem o efeito da pobreza, como se isso fosse, segundo os autores, a única função dos programas de suplementação alimentar. O nutricionista tem oportunidade de desenvolver seu potencial como educador em nutrição e de criar "condições para tornar o ambiente onde quem atua também ensina e aprende, num empenho conjunto na busca por melhores condições de saúde".

Nesse sentido, tais perspectivas de atuação do nutricionista ampliam a importância de se implementarem programas de formação que visem aprimorar as competências desse profissional nesse campo. Considerando tal demanda, o CECANE-UFBA vem desenvolvendo, desde
2007, atividades de formação para nutricionistas em estados da Região Nordeste, e também para merendeiras e componentes do CAE.

Assim, o Programa foi realizado envolvendo esses atores no mesmo polo de formação, objetivando: contribuir para a eficácia e efetividade do PNAE, a fim de promover o alcance dos seus princípios e diretrizes; estimular a reflexão sobre o papel dos agentes envolvidos; possibilitar o reconhecimento e a reflexão acerca do referencial teórico e legal necessário para o exercício profissional; apoiar ações que possibilitem a melhoria na execução do Programa; valorizar e incentivar a construção de parcerias que fortaleçam e otimizem as ações no âmbito do PNAE. Dentre as temáticas trabalhadas, destacam-se: alimentação como direito social, segurança alimentar e nutricional, controle social da política de alimentação, normas e técnicas para gestão do PNAE, diagnóstico nutricional dos escolares, educação nutricional para escolares e alimentação e cultura.

A realização simultânea dos programas para nutricionistas, merendeiras e conselheiros possibilitou o desenvolvimento de uma metodologia com vistas à interação entre os três segmentos, fomentando a aproximação e o diálogo entre eles. Assim, planejaram-se atividades conjuntas, dentre as quais dinâmicas em grupos mistos, com perguntas/respostas e exposição dialogada sobre os diferentes temas. Tal planejamento propiciou espaço para a fala dos participantes acerca das suas experiências no cotidiano do trabalho e, com isso, a troca de ideias.

Ademais, com o objetivo de motivar os agentes a planejarem ações necessárias à sua prática a partir das reflexões incitadas nos programas de formação, elaborou-se uma estratégia metodológica que fomentasse a construção de um plano de ação. Esperava-se com esse recurso contribuir para o planejamento e execução de ações que possibilitassem aperfeiçoar qualitativamente o PNAE, além de colaborar para o resgate do compromisso do agente no âmbito das suas 
responsabilidades e para a integração dos vários segmentos no conjunto das ações desenvolvidas.

Tendo em vista a necessidade de avaliação do Programa de Formação proporcionado aos nutricionistas, foi criada uma estratégia como forma de monitoramento. Ela foi desenvolvida após transcorridos ao menos três meses da sua finalização, durante o Programa de Educação Permanente para nutricionistas do PNAE (PEPINUT). Partiu-se do pressuposto de que a avaliação realizada após retorno ao lócus de trabalho poderia apreender outros aspectos referentes à capacidade de um programa de formação instituir mudanças no cotidiano do trabalho, aspectos impossíveis de serem apreendidos em uma análise durante ou imediatamente após o final da formação.

Nesse sentido, o presente artigo objetivou analisar os resultados relativos à avaliação do Programa de Formação em questão, os quais foram produzidos através de grupos focais. Destaca-se que o PEPINUT caracterizou-se por ser outro modelo experimental de formação específica, destinada aos nutricionistas que atuam no PNAE nos estados da Região Nordeste. Esse Programa baseou-se nos princípios da Educação Permanente em Saúde (EPS), sendo um modelo desenvolvido em imersão com 40h de duração, que visava ampliar e aprofundar as temáticas trabalhadas nos programas precedentes.

A EPS fundamenta-se no campo de formação dos recursos humanos em saúde e possui como objeto de transformação o processo de trabalho, o qual é revalorizado como centro privilegiado da aprendizagem. Assim, reflete-se sobre o que ocorre no serviço e o que necessita ser transformado, considerando-se a primazia do sujeito enquanto produtor do sentido da experiência. Assim, o processo de trabalho em saúde apresenta-se como eixo que define e configura demandas educacionais, as quais incluem elementos importantes como a organização do mundo do trabalho e as representações sociais sobre esse trabalho ${ }^{8}$.

Em sua dimensão estratégica, pode-se situar a EPS como atividade técnica e política, sendo necessário não subestimar a dimensão da subjetividade e do conflito de interesses ${ }^{8}$. A EPS contribui então para atuação crítica, reflexiva, propositiva, compromissada e tecnicamente competente no espaço do trabalho, sendo estratégia fundamental às transformações deste ${ }^{9}$. Vale ainda sinalizar que a avaliação é uma das etapas previstas no planejamento de projetos educativos ${ }^{10}$ e que a avaliação processual, tendo em vista a qualificação do processo de educação permanente, tem sido de valor inestimável ${ }^{11}$.

\section{MÉ TO D O S}

Foram realizados dois PEPINUT no ano de 2008, um no período de 14 a 18 de julho e outro no período de 28 de julho a $1^{\circ}$ de agosto. No total, participaram 56 nutricionistas dos Estados de Bahia, Sergipe, Alagoas e Pernambuco, tendo ambos os eventos sido realizados na Escola de Nutrição da UFBA, localizada em Salvador. A seleção dos nutricionistas atendeu aos seguintes critérios: estar trabalhando no PNAE; ter participado do Programa de Formação em 2007 ou 2008; ter demonstrado interesse em participar da proposta de aprofundamento, por solicitação de vaga via e-mail ou por escrito; apresentar disponibilidade no período solicitado; e ter colaboração do gestor local para custear as passagens de deslocamento entre o município de atuação e a cidade de Salvador.

Cabe salientar que o presente estudo não pretendeu ser representativo do universo dos nutricionistas que haviam participado do Programa de Formação. O propósito, ao se tratar de um estudo qualitativo, foi capturar, a partir da fala dos sujeitos dialogando nos grupos focais, os significados da experiência formativa que eles vivenciaram

A experiência da formação foi avaliada por meio de grupos focais, cujo objetivo central foi verificar se, depois de transcorridos ao menos três meses, o Programa de Formação estava sendo capaz de instituir mudanças no cotidiano do trabalho dos nutricionistas. Destaca-se que, no total, 
haviam participado do Programa de Formação 614 nutricionistas, ao longo dos anos de 2007 e 2008, nos Estados de Bahia, Alagoas, Ceará, Maranhão, Piauí, Pernambuco, Rio Grande do Norte, Paraíba e Sergipe.

Ressalta-se que os grupos focais, enquanto instrumentos de avaliação, possibilitam gerar impressões sobre programas, serviços, instituições, produtos ou outros objetos de interesse ${ }^{12}$. Essencialmente, em um grupo focal há a interação entre os participantes e o pesquisador/moderador que, através do diálogo, focado em tópicos específicos e diretivos, objetiva a obtenção de dados sobre a problemática em questão ${ }^{13}$. Segundo Stewart \& Shamdasani ${ }^{12}$, a maioria dos grupos focais é constituída de seis a doze pessoas, pois se considera que um grupo maior não oferece oportunidade suficiente para que todos os indivíduos participem ativamente.

Dentre as vantagens do grupo focal destacam-se: o fornecimento de dados por um grupo de pessoas é mais rápido e menos oneroso do que em entrevistas individuais; o efeito sinérgico do grupo pode resultar na produção de dados ou ideias não descobertos em entrevistas individuais; pode ser usado para examinar uma ampla gama de tópicos, com variedade de indivíduos e diversidade de cenários; pode ser utilizado para obtenção de dados provenientes de crianças ou indivíduos com baixa escolaridade ${ }^{12}$.

No que tange às suas desvantagens, sinalizam-se: oferece restrição para a generalização dos resultados; os dados podem ser enviesados pela participação de um membro que opine mais; a natureza aberta das respostas obtidas frequentemente dificulta a sumarização e interpretação dos resultados; o moderador pode favorecer viés intencional ou não, ao gerar insinuações sobre quais tipos de respostas e perguntas são desejáveis ${ }^{12}$.

Foram realizados quatro grupos focais, dois em cada período, cada um com cerca de uma hora de duração, contemplando os nutricionistas participantes dos PEPINUT mencionados. Os grupos foram conduzidos por uma nutricionista inte- grante do CECANE-UFBA, responsável pelo processo avaliativo do Programa de Formação, a qual realizou o papel de moderador. As atividades tiveram apoio de estudantes do curso de graduação da Escola de Nutrição da UFBA e de bolsistas do CECANE, que efetuaram a gravação das falas dos participantes, o registro de notas e, posteriormente, a transcrição do material empírico.

O roteiro do grupo focal foi construído a partir de três questões motivadoras: (1) como foi a experiência do Programa de Formação e quais foram os principais marcos, pontos positivos e dificuldades; (2) se o programa gerou possibilidades de mudanças; e (3) o que efetivamente mudou no cotidiano do trabalho após a formação.

Em relação ao perfil dos nutricionistas participantes do PEPINUT em 2008, destaca-se que predominaram profissionais do sexo feminino, com idade entre 20 e 35 anos e que trabalhavam há menos de um ano no Programa. Além disso, um terço era recém-egresso das universidades, não apresentando experiência profissional prévia.

Após transcrito o material, foram realizadas leituras exploratórias, organizando-o em duas grandes categorias de análise - a aprendizagem durante a formação e a capacidade de instituição de mudanças - cada qual com subcategorias e dimensões. De modo a garantir a privacidade dos sujeitos e a autorização para publicação dos resultados, todos os participantes assinaram o Termo de Consentimento Livre e Esclarecido (TCLE). O estudo foi aprovado pelo Comitê de Ética em Pesquisa da Maternidade Climério de Oliveira, da Universidade Federal da Bahia, Parecer/Resolução no 111/2007, em 17 de agosto de 2007.

\section{RESULTADOSE DISCUSSÃO}

\section{Aprendizagem durante a formação}

Desde as primeiras sondagens realizadas no Programa de Formação, um aspecto fulcral para os nutricionistas é a questão do isolamento profissional como um problema, uma vez que eles 
são responsáveis técnicos pelo programa em um município e, em geral, não dispõem de outros nutricionistas no quadro técnico. É um sentimento largamente compartilhado por todos, aliado ainda à falta de preparo adequado para o trabalho no PNAE durante o curso de graduação, segundo o relato dos participantes.

Para mim (referindo-se ao Programa), foi uma luz, porque, no meu caso, eu não sabia nada a respeito do PNAE, na graduação eu nunca vi uma aula, um texto que falasse sobre o PNAE, então eu não tinha o conhecimento... . Foi a partir dali que eu realmente comecei a atuar no PNAE, porque antes eu estava meio perdida... (GF1).

Esse aspecto está relacionado a um dos primeiros marcos do Programa de Formação: a oportunidade de interação com os demais profissionais, proporcionando uma troca de experiências. A atividade inicial do Programa de Formação denominada "Eu e o nutricionista" teve como objetivo que os participantes, organizados em pequenos grupos, se apresentassem e dialogassem sobre as suas experiências, buscando identificar qual era o lugar de cada um enquanto profissional no Programa de Alimentação Escolar. Essa troca permitiu não só compartilhar os problemas enfrentados no cotidiano do trabalho, mas também aprender com o outro, em suas experiências exitosas ou não, possibilitando reproduzir e/ou reconstruir ações adequadas à realidade em que cada qual atua: A troca de experiências, a experiência das colegas contribui para a gente buscar alternativas... (GF2).

O que achei muito interessante foi a relação com outros profissionais, porque o nutricionista do PNAE trabalha muito isolado, não tem como trocar ideias com outros nutricionistas, então a gente pensa que só o nosso município passa por determinados problemas. Isso pode ser triste, mas foi bom ver que vários municípios passam pelo mesmo problema que eu... (GF1).

Dessa maneira, a troca de experiências foi bastante valorizada nos depoimentos dos partici- pantes, contrapondo-se às metodologias de trabalho em que eles "apenas escutam", conforme relatado. A existência de espaços para se expressar foi considerada importante para a formação.

Destaca-se que no desenho de práticas educativas é necessário conhecer o outro e encontrar a racionalidade que conduz seu pensamento e sua ação. Os profissionais de saúde têm diferentes visões sobre o mundo, e as práticas desenvolvidas no trabalho são coerentes com essas visões ${ }^{8}$. Soma-se a isso um aspecto inerente ao processo de educação permanente, em que a formação deve partir de um trabalho de reflexão crítica sobre as próprias práticas, o que contribui para pensar a própria identidade profissional - e não apenas por meio da transmissão e acumulação de conhecimentos, tal como no modelo tradicional de educação. É refletindo sobre sua própria prática que o sujeito se reconhece como tal, tendo o diálogo o papel mediador no processo $^{14}$.

Essas possibilidades dialógicas também foram marcantes, segundo o relato dos grupos, em outras atividades da formação. As exposições dialogadas, por exemplo, foram referidas como espaços de debate em relação aos temas abordados:

E a maneira como acontece nas capacitações, a questão do ouvir, que a gente é ouvido por vocês, um momento que eu achei muito legal na capacitação... a gente pensa então que quando nós estamos treinando as merendeiras a gente tem que ouvi-las, isso é muito importante (GF3).

A fala acima revela que a própria metodologia utilizada na formação foi também um elemento de aprendizagem, que pôde ser utilizado por alguns profissionais, por exemplo, em programas de formação de merendeiros, uma das atribuições do nutricionista no PNAE.

Nos grupos focais foram também referidas as atividades que envolveram nutricionistas, merendeiras e conselheiros no mesmo polo de formação. As atividades conjuntas foram consideradas 
bastante positivas, tanto por possibilitar o compartilhamento das experiências vivenciadas no âmbito do PNAE, quanto por proporcionar o conhecimento sobre os papéis de cada um desses atores e por contribuir para uma maior valorização dos parceiros de trabalho:

A capacitação foi excelente por isso, porque não foi feita somente com as nutricionistas, mas também com o Conselho e, consequentemente, a gente conseguiu essa interação no meu município (GF1).

Após a capacitação no meu município, houve uma união entre o $C A E$, as merendeiras e as nutricionistas. Foi bom porque eles perceberam qual era o papel de cada um dentro do Programa (GF4).

Eu percebi que as merendeiras hoje me procuram, porque com a capacitação elas se sentiram mais valorizadas e passaram a trabalhar melhor (GF3).

Vale ainda ressaltar que a troca de experiências não se deu apenas durante as atividades previstas, mas também nas próprias relações construídas entre as parcerias de hospedagem e convivência fora do horário de formação. Embora esses espaços sejam em geral subestimados nos processos formativos, eles contribuem para conformação de relações intersubjetivas, instituindo elos e diálogos importantes para a formação.

Outro ponto a ser destacado diz respeito à aprendizagem mais significativa relatada por todos os grupos: a "mudança na maneira de pensar" , a "tomada de consciência" de seu papel enquanto profissional. Essa maneira de pensar trouxe uma espécie de autovalorização profissional expressa de diferentes formas, como "após a capacitação eu voltei bem mais fortalecida", "sentir-se mais seguro" e, sobretudo, reconhecer qual é o seu papel no Programa. "A questão do papel de cada um, a capacitação ajudou a definir papéis, porque às vezes a gente quer que tudo funcione e terminamos deixando de fazer o nosso papel de nutricionista" (GF2).
Em suma, observa-se que a dimensão do diálogo perpassa o processo formativo e que ele foi visto como um dos pontos mais relevantes do Programa de Formação - seja o diálogo com os nutricionistas, com os demais atores, ou ainda com os mediadores da formação nas exposições dialogadas. É importante lembrar que o diálogo fundamenta o ato educativo, representando a pedra angular do encontro dos sujeitos, a condição essencial para a existência humana. O diálogo, desse modo, apresenta-se como uma exigência ontológica universal e ainda como uma via para a promoção da emancipação humana e a transformação social ${ }^{15}$. Além disso, é através das práticas dialógicas que o sujeito se reconhece no seu mundo e, nesse caso em particular, no mundo do trabalho.

No que tange à exposição dialogada, foi citada como importante a abordagem dos seguintes temas: o processo de licitação para a compra de gêneros da alimentação escolar, que pareceu ser um dos mais desafiantes em função de um expressivo desconhecimento dos nutricionistas sobre o assunto; a implantação do Sistema de Vigilância Alimentar e Nutricional (SISVAN) Web; a execução do Programa de Aquisição de Alimentos (PAA); a visita técnica aos fornecedores; a construção de parcerias; o programa de hortas comunitárias, vinculado ao Projeto Educando com a Horta Escolar (PEHE); a inserção dos produtos da agricultura familiar nos cardápios.

Todavia, chamou a atenção nas falas que, além do aprimoramento de conhecimentos sobre temas pertinentes ao programa de alimentação escolar, do reconhecimento do papel do nutricionista e da valorização da sua própria atuação profissional, algumas habilidades profissionais mais genéricas foram também fontes de aprendizagem. A primeira foi a ampliação do poder de argumentação baseada em fundamentos teóricos e legais do Programa, e a segunda referiu-se à formalização das solicitações junto aos órgãos competentes como uma necessidade de registrar e documentar tudo que é desenvolvido, por meio de relatórios, ofícios e outros substratos legais: 
"E uma coisa que foi bem frisada na capacitação foi a necessidade de se documentar tudo e de arquivar também".

Vejam-se outros exemplos de como a lógica da documentação perpassa várias ações:

Quando eu voltei, conversei com a coordenadora da merenda e falei para ela que agora tudo que nós fossemos pedir teria que se documentar para o gestor, ela assina ciente (GF3).

A capacitação mostrou a necessidade em se conhecer a clientela, fazer avaliação nutricional, as patologias da nossa clientela. Eu solicitei que essas patologias fossem documentadas, e eu criei um relatório para que no dia da matrícula a gente possa colher essas informações, para que a gente possa fazer um diagnóstico da nossa população (GF2).

A questão do conhecimento mesmo, assim que voltei da capacitação, eu fiz um relatório com o que eu vi que estava irregular, fui ao $C A E$, e assim às vezes a gente fica esperando, mas a gente tem que ir atrás mesmo (GF4).

Os trechos revelam que o Programa de Formação trouxe o eixo do trabalho e da sua organização cotidiana como fundante do processo de ensino-aprendizagem. Em outras palavras, não se tratou de discutir apenas as competências técnico-científicas inerentes à prática do nutricionista de forma restrita, mas também aspectos gerais que conformam o trabalho, englobando ainda as dimensões ético-políticas e socioeducativas.

\section{Capacidade de instituiç̧ão de mudanças}

Em relação ao questionamento referente à capacidade de o Programa de Formação instituir mudanças após o retorno ao lócus do trabalho, as respostas dos participantes divergiram. Estes consideraram que tal possibilidade depende das relações de poder estabelecidas no local do tra- balho e da realidade de cada município; assim, por vezes, a dimensão da política local prepondera sobre a dimensão técnico-profissional. Há uma espécie de frustração coletiva do querer "fazer alguma coisa e não ter oportunidade". Alguns relatos apontaram tal dificuldade:

Em meu município é tudo centralizado, vem tudo pronto, então eu gostaria de mudar isso, a fim de controlar a questão da qualidade e do transporte (dos gêneros alimentícios), mas tem a questão de tentar modificar a estrutura do local que eu trabalho, a questão da compra, que é complicado... . Então tem estes entraves mesmo, mas a gente está aqui para aprender, tanto que fiz questão mesmo, briguei para vir, deixei o material preparado e vim... (GF3).

Eu não tenho uma equipe técnica que possa me ajudar, porque na capacitação eu descobri o que é o Programa, e qual a responsabilidade do nutricionista, e eu descobri que nós temos que nos desdobrar a mil, e temos muitas dificuldades, o Conselho aparece, eles não sabem quais são as suas atribuições, então na verdade sou eu para tudo (GF1).

A gente aprendeu bastante na capacitação, mas a gente não tem apoio nem capacidade de pôr tudo em prática, então fica tudo no papel (GF3).

Destaca-se que um dos grandes problemas apontados nos cursos de formação é que eles são eminentemente teóricos, trabalhando a perspectiva do "como deveria ser", por vezes distante da realidade vivenciada no cotidiano das práticas. Ribeiro \& Mota ${ }^{8}$ discorrem sobre o tema, ressaltando que nos cursos de atualização há uma espécie de tradução da verdade do conhecimento científico acumulado e atualizado, aplicável numa espécie de representação universal e única. Todavia, quando os profissionais retornam a seu serviço e confrontam-se com sua realidade cotidiana, eles observam ser impossível a aplicação do conhecimento adquirido. Dessa maneira, os cursos, que 
podem ser considerados importantes durante a sua vigência, podem ao mesmo tempo ser considerados frustrantes na tentativa de sua utilização como instrumento de mudança das práticas cotidianas do trabalho.

Estudo que analisa o processo de aprendizagem-trabalho por meio da Educação Permanente de equipes multiprofissionais da Estratégia de Saúde da Família ressalta em seus resultados o reconhecimento dos profissionais, no que se refere às situações de qualificação, quanto à necessidade de práticas pedagógicas problematizadoras que possibilitem ir além do "como devia ser". Esses profissionais enfatizam que há diferentes realidades nos serviços, o que impossibilita a aplicação de diversos conhecimentos adquiridos, tanto por limitações relativas à relação entre os diversos atores sociais envolvidos, quanto por limitações no processo de trabalho ${ }^{16}$.

Nos grupos focais, foi aludida ainda a importância de sensibilizar os gestores, tendo em vista estimular o reconhecimento acerca da relevância do Programa em todos os seus sentidos. Os participantes sugeriram que os mesmos também deveriam participar dos programas de formação, particularmente aqueles que possuem em seus municípios maiores dificuldades estruturais. Entretanto, destacaram que a participação de diferentes atores de um mesmo município no Programa de formação, por si só, trouxe impacto positivo em relação à visão dos gestores acerca do papel do PNAE para o escolar e do papel do nutricionista no Programa.

Por outro lado, a grande maioria conseguiu instituir algumas mudanças que, embora consideradas pequenas, foram significativas e impactantes. As mudanças representaram mais tentativas em "fazer alguma coisa", a exemplo do que foi proposto na construção do plano de ação, que representou uma forma de trabalhar com metas e objetivos, fornecendo uma direção para as ações profissionais. Nessa perspectiva, os participantes enfatizaram a relevância de serem abordadas as técnicas para gestão do PNAE:
Já fiz parceria com a Secretaria de Saúde e com a Vigilância Sanitária, e vou fazer avaliação nutricional dos alunos com o SISVAN-WEB (GF3).

O meu município não recebia verba do CONAB, e com a capacitação eu descobri esta informação que eu não tinha... Então foi uma luta grande... eu tinha feito o teste de aceitabilidade no município, mas não tinha feito o plano de ação, então quando eu voltei da capacitação fiz logo o plano de ação (GF2).

Antes da capacitação a gente não recebia avental, touca, as botas, nada disso era dado, e a gente já está conseguindo pequenas coisas, já está melhorando muito. Então estas pequenas coisas eu consegui, mas coisas mais sólidas não... (GF1).

A gente fez o plano de ação junto ao Conselho. A resposta no município quando nós temos o apoio do Conselho é diferente... (GF4).

Pode-se observar que o Programa de Formação trouxe novos conhecimentos e nova ótica de observação acerca das questões relacionadas ao PNAE, bem como estimulou a reflexão sobre as ações desenvolvidas no município que precisam ser revistas. Isso é constatado em relatos como "logo quando cheguei, medidas já foram sendo tomadas" e "este ano eu iniciei com outra visão por causa da capacitação". Observa-se também que as ações foram de pequena escala, modestas, entretanto trazendo melhorias no processo de trabalho.

A perspectiva de ações em pequena escala foi um dos pontos trabalhados no Programa de Formação. Sinaliza-se ainda que as experiências exitosas são exemplos a serem dialogados e não necessariamente reproduzidos, uma vez que os contextos são diferenciados. Assim, a discussão coletiva foi um marco, como pode ser observado no seguinte relato "... uma coisa é você pegar a legislação para ler e outra coisa é você ficar discutindo com outras pessoas...". Em suma, são 
as condições de produção do trabalho que irão gerar as soluções mais pertinentes para a melhoria do Programa. Para tanto, cabe aos profissionais aprimorar seu olhar acerca da realidade, alimentado pelos conhecimentos técnico-científicos e pela capacidade reflexiva.

Belik \& Chaim¹', ao realizarem análise sobre a execução do PNAE em cidades inscritas no Prêmio Gestor Eficiente da Merenda Escola, observaram que sua gestão assume características próprias, a depender do contexto de cada município. Os autores enfatizam ainda que a gestão, quando realizada de forma compartilhada entre os diferentes atores envolvidos no processo, gera um impacto positivo em diversas áreas contempladas no Programa, como a nutricional e a social.

Vale ainda considerar que, dada a complexidade do desenvolvimento do trabalho e o pouco tempo entre a formação e o momento de realização desta avaliação, o mesmo não foi suficiente para provocar impactos substanciais no cotidiano do Programa.

\section{O N C L U S Ã O}

No que tange à avaliação do Programa de Formação na perspectiva dos participantes, podese afirmar que ele proporcionou um aprimoramento técnico-científico em torno dos temas pertinentes não só à prática profissional, mas também à dimensão ético-política do trabalho. Enfatiza-se ainda que ele estimulou a mobilização e a perspectiva de fortalecimento da categoria, incentivou as parcerias entre os diferentes agentes e setores, como os da educação e saúde, e fomentou o planejamento de novas ações, valorizando o uso da legislação e das portarias interministeriais.

A perspectiva dialógica foi marcante para os participantes dos grupos, que puderam confrontar a sua realidade com a dos demais, possibilitando uma reflexão coletiva sobre a atuação do nutricionista no campo da alimentação escolar. A expressão mais significativa desse processo de ensino-aprendizagem foi: "a mudança na maneira de pensar". Esta trata do pensar sobre si e sua relação com o mundo do trabalho, relacionada a uma autoafirmação da categoria, na medida em que os nutricionistas ampliaram sua visão em relação a seu papel profissional.

Essa questão corrobora a perspectiva de que o aumento ou atualização de conhecimentos não fornecem condição suficiente para a transformação das práticas institucionais por si sós. É necessário trabalhar outros campos das habilidades profissionais, isto é, além do saber, o saber fazer, o saber ser e o saber conviver, os quatro pilares da educação no século XXI. A imbricação entre eles contribuirá para a (re)construção das práticas profissionais e, consequentemente, das relações profissionais, o que possibilitará mudanças nos processos de trabalho. Não se trata então de uma relação simplista entre o saber e o fazer, mas sim de uma relação complexa que se torna um desafio.

Isso reforça a ideia de educação permanente como espaço de ação-reflexão importante para o avanço das práticas sociais. Sinaliza ainda - para o aparelho formador, para o gestor e para o órgão central - a importância da sintonia com os anseios e as necessidades sociais.

Em relação à experiência de avaliação desenvolvida, dois aspectos são relevantes: o lapso de três meses depois de realizado o Programa e a utilização dos grupos focais. O primeiro trouxe a vantagem de efetuar a análise após um tempo de vivência no lócus de trabalho, com a possibilidade de o nutricionista já ter experimentado alguma estratégia aprendida na formação. Dessa forma, atende à expectativa dos gestores de Programas de Formação quanto à possibilidade de se instituírem mudanças no mundo do trabalho. Já sobre o segundo aspecto, salienta-se que a técnica de grupos focais mostrou-se eficaz ao propiciar o diálogo coletivo sobre os limites e viabilidades que a formação foi capaz de proporcionar aos profissionais envolvidos. Tem-se aqui um modelo de avaliação que também constitui um processo de aprendizagem, na medida em que os sujeitos são instigados a refletir sobre sua própria formação. 


\section{COLABORADORES}

LR Sampaio, AL Mello, GAV Fontes e MCS Freitas trabalharam na concepção do projeto, delineamento metodológico e elaboração do artigo. LAS Santos trabalhou nas etapas anteriores, moderação dos grupos focais, análise e interpretação dos dados e redação do artigo. JB Paiva trabalhou na interpretação dos dados, elaboração e redação do artigo.

\section{A GRADECIMENTOS}

Este Programa foi desenvolvido pelo Centro Colaborador em Alimentação e Nutrição do Escolar da Universidade Federal da Bahia (CECANE-UFBA), em parceria e com financiamento do Fundo Nacional de Desenvolvimento da Educação, Ministério da Educação (FNDE/MEC). Trata-se de um trabalho original. Aos nutricionistas participantes do Programa de Formação e do PEPINUT; à equipe administrativa do CECANE-UFBA.

\section{REFERÊ N CIAS}

1. Belik W, Chaim NA. O programa nacional de alimentação escolar e a gestão municipal: eficiência administrativa, controle social e desenvolvimento local. Rev Nutr. 2009; 22(5):595-607. doi: 10.1590/ S1415-52732009000500001.

2. Brasil. Lei $n^{\circ} 11.947$, de 16 de junho de 2009. Dispõe sobre o atendimento da alimentação escolar e do Programa Dinheiro Direto na Escola aos alunos da educação básica; altera as Leis $n^{\circ} 10.880$ de 9 de junho de 2004, 11.273, de 6 de fevereiro de 2006, 11.507, de 20 de julho de 2007; revoga dispositivos da Medida Provisória $n^{\circ} 2.178-36$, de 24 de agosto de 2001, e a Lei $n^{\circ} 8.913$, de 12 de julho de 1994; e dá outras providências. Diário Oficial da União. 200917 jun; p.2, Seção1.

3. Brasil. Alimentação escolar: dados estatísticos. [acesso 2010 out 10]. Disponível em: <www.fnde. gov.br>.

4. Brasil. Resolução FNDE/CD n 38, de 16 de julho de 2009. Dispõe sobre o atendimento da alimentação escolar aos alunos da educação básica no Programa Nacional de Alimentação Escolar - PNAE. Diário Oficial da União. 200917 jul.

5. Conselho Federal de Nutricionista. Resolução CFN $n^{\circ} 465 / 2010$. Dispõe sobre as atribuições do nutricionista, estabelece parâmetros numéricos mínimos de referência no âmbito do Programa de Alimentação Escolar e dá outras providências. Diário Oficial da União. 201025 ago.
6. Conselho Federal de Nutricionista. Resolução CFN n³80/2005. Dispõe sobre a definição das áreas de atuação do nutricionista e suas atribuições, estabelece parâmetros numéricos de referência, por área de atuação, e dá outras providências. Diário Oficial da União. 200610 jan.

7. Costa EQ, Ribeiro VMB, Ribeiro ECO. Programa de alimentação escolar: espaço de aprendizagem e produção do conhecimento. Rev Nutr. 2001; 14(3): 225-29. doi: 10.1590/S1415-52732001000300 009.

8. Ribeiro ECO, Motta Jl. Educação permanente como estratégia de reorganização dos serviços de saúde. Div Saúde Debate. 1996; 12(0):24-30.

9. Cecim RB. Educação permanente em saúde: descentralização e disseminação da capacidade pedagógica na saúde. Ciênc Saúde Coletiva. 2005; 10(4):975-86. doi: 10.1590/\$1413-81232005000 400020 .

10. Soares CB, Reale D, Brites CM. Uso de grupo focal como instrumento de avaliação de programa educacional em saúde. Rev Esc Enferm USP. 2000; 34(3):317-22. doi: 10.1590/S0080-623420000003 00014.

11. Feliciano KVO, Kovacs MH, Costa IER, Oliveira MG, Araújo AMS. Avaliação continuada da educação permanente na atenção à criança na estratégia saúde da família. Rev Bras Saúde Matern Infant. 2008; 8(1):45-53. doi: 10.1590/\$1519-38292008 000100006 .

12. Stewart DW, Shamdasani PN. Focus groups: theory and practice. London: Sage; 1990.

13. lervolino AS, Pelicioni MCF. A utilização do grupo focal como metodologia qualitativa na promoção da saúde. Rev Esc Enferm USP. 2001; 35(2):115-21. doi: 10.1590/S0080-62342001000200004.

14. Abramowicz M. A importância dos grupos de formação reflexiva docente no interior dos cursos universitários. In: Castanho S, Castanho ME, organizadores. Temas e textos em metodologia do ensino superior. Campinas: Papirus; 2001.

15. Santos LAS. Texto-Síntese. Anais do II Fórum de Educação Alimentar e Nutricional para a Promoção da Saúde e Direito Humano à Alimentação Adequada: contribuições para o debate. CGPAN/MS; 2008 nov 14; Brasília.

16. Pessanha RV, Cunha FTS. A aprendizagem-trabalho e as tecnologias de saúde na estratégia de saúde da família. Texto Contexto Enferm. 2009; 18(2): 233-40. doi: 10.1590/S0104-07072009000200 005.

Recebido em: 25/1/2011

Versão final reapresentada em: 7/12/2011 Aprovado em: 9/1/2012 
